\title{
GRANDES PROJETOS URBANOS NO BRASIL: CONCEITOS, CONTEXTUALIZAÇÃO E DISCUSSÃO DE TRÊS CASOS
}

Clovis Ultramari ${ }^{1}$

\section{RESUMO}

Este artigo revê algumas considerações conceituais a respeito dos chamados Grandes Projetos Urbanos, inicia uma discussão sobre essas intervenções no cenário urbano brasileiro e, por último, discute três exemplos, a partir de publicações de outros pesquisadores anteriormente elaboradas e que discutem os projetos da orla de Belém do Pará, a recuperação do bairro lagoinha, em Belo Horizonte, e as intervenções em Baltimore, EUA.

\section{PALAVRAS-CHAVE}

Grandes Projetos Urbanos, Intervenções Urbanísticas.

\section{ABSTRACT}

This paper reviews some conceptual aspects of the Urban Megaprojects, proposes to develop further this discussion in the Brazilian urban scenario and, presents analyses made to three different interventions by other researchers: projects to the riverside - waterfront interventions - in Belém do Pará, the revitalization of Lagoinha district, in Belo Horizonte and interventions made in Baltimore, USA.

\footnotetext{
${ }^{1}$ Arquiteto, doutor em Meio Ambiente e Desenvolvimento, pela Universidade Federal do Paraná, em 2001 e Professor de urbanismo da Universidade Católica do Paraná. Contato: ultramari@yahoo.com
} 


\section{KEY WORDS}

Urban Megaprojects, Urban Renewal, Urban Intervention

\section{INTRODUÇÃO}

O presente artigo procura contribuir para a discussão sobre os chamados Grandes Projetos Urbanos, mais especificamente sua contextualização no Brasil por meio de estudos já realizados sobre dois exemplos observados em nossas cidades e um terceiro, norte-americano, considerado referencial histórico recente. Ostensivamente presentes na Europa, nos Estados Unidos e em países emergentes, tais projetos têm caracterizado uma nova fase do urbanismo moderno, precocemente reconhecida como Renascença Urbana. Em países como o Brasil, tais intervenções na paisagem urbana concorrem com outros tipos de ação consideradas básicas à vivência urbana, tendo portanto reduzidas suas influências no cenário de nossas cidades. Assim, são reduzidas suas influências na malha urbana e ainda despertam pouco interesse da parte dos urbanistas brasileiros. Ao se analisar esses estudos, na maioria das vezes, limitam-se a um foco sobre os altos custos da obra, no lucro apropriado pelo setor privado e na relação discutível com outras ações governamentais.

Não concordo com o museu [Museu do Olho, hoje Museu Oscar Niemeyer, em Curitiba, inaugurado em 2001]. Deveriam ser construídas muito mais coisas: creche ou lazer para os mais pobres .... ao invés de museu, investiria na saúde pública: hospital, posto de saúde, farmácia pública ... Construiria uma Universidade pública ao invés de museu (Clovis Ultramari, 2005, entrevista com os operários do museu $)^{2}$

De fato, no meio urbano brasileiro, o impacto de tais obras acaba por ser reduzido devido a outras ações de uma eventual política urbana nacional, caso se possa realmente considerar a práxis atual como resultado de uma política concertada. Tal ação política, ou seja, o cenário no qual os Grandes Projetos Urbanos são implementados, ainda que não formalmente constituída pode ser assim sintetizados: 1. controle de uso do solo (antiga prática do planejamento urbano que agora concorrem com o chamado Planejamento Estratégico); 2. planejamento participativo (vide atuais

\footnotetext{
${ }^{2}$ Observações como essa foram observadas na pesquisa realizada junto a 28 operários, na véspera da inauguração da obra. Posições contrárias também puderam ser encontradas junto aos operários da obra do museu. A pesquisa ocorreu na véspera da inauguração da obra.
} 
esforços de se generalizar a elaboração de Planos Diretores participativos pelo Ministério das Cidades e por alguns governos estaduais $\left.{ }^{3}\right)$; 3. projetos de atendimento à demanda urbana básica (sobretudo com recursos do Banco Mundial e do Banco Interamericano, maiores financiadores de projetos urbanos no Brasil, com prioridade para as áreas de saneamento, habitação e transporte) e; 4. priorização de regularização de áreas invadidas (tentativas diversas de aplicação do Estatuto da Cidade, o qual facilita a legalização de tais assentamentos).

Meio a esse conhecido cenário de regularização, participação comunitária, atendimento deficitário a áreas carentes de infra-estrutura, regulação urbanística e elaboração de Planos que revisitam o chamado "planejamento de gaveta" dos anos 70, os Grandes Projetos Urbanos no Brasil ainda despertam pouco interesse entre estudiosos e, diferentemente de outros países, são pontuais e, infelizmente, não constituem partes integrantes de projetos estratégicos capazes de alterar o todo urbano das cidades onde são implementadas.

A despeito de os megaprojetos urbanos ainda não contarem com exemplos que possam indicar transformações generalizadas nas cidades brasileiras, como parecem ser os já clássicos casos de Baltimore, Barcelona, Manchester, Bilbao, dentre outros, observam-se exemplos de mudanças em algumas cidades de nosso território e que têm contribuído significativamente para a melhoria nas relações entre espaço construído e cidadão. Todavia, ainda que sejam exemplos concentrados nas áreas centrais de nossas cidades, talvez pelo menor valor relativo que implicam, tais obras temporariamente se resguardam de críticas como aquelas - recorrentes na crítica norteamericana - feitas por David Harvey, a partir dos exemplos observados em Baltimore:

This is what is called "feeding the downtown monster". Every new wave of public investment is needed to make the last wave pay off. The private public partnership means that the public takes the risks and the private takes the profits. (David Harvey, 2000), $p$ 141)

A deficiência ou mesmo a falta deste debate faz com que os Grandes Projetos Urbanos sejam discutidos tão-somente a partir de seus custos, raramente compondo uma discussão mais ampla da cidade, aí incluindo a sua virtual capacidade de alavancarem mudanças maiores que aquelas observadas nas suas reconhecidas áreas de impacto imediato. Sempre polêmicos, tais projetos podem servir para consubstanciar um debate maior sobre a cidade a partir de questões facilmente

\footnotetext{
${ }^{3}$ O governo do Estado do Paraná, gestão 2002-2006, sujeita o repasse de recursos aos municípios à elaboração de Planos Diretores em atendimento ao Estatuto da Cidade. Para tanto tem disponibilizado recursos aos municípios. Ainda que os municípios não sejam obrigados pela legislação federal a elaborarem seus PDs, repasses financeiros do governo ficam sujeitos a essa elaboração.
} 
compreendidas pela população sob impacto imediato de suas implementações. Nesse caso, estar-seia fazendo o que planos mais ambiciosos têm buscado, ou seja, uma discussão sobre o futuro das cidades com a participação dos diversos agentes envolvidos. Manuel Castells e Jordi Borja (1996) talvez tenham sido um dos maiores difusores dessas idéias, assinalando que a cidade passa a ser protagonista econômica e social, dinamizadora de bens simbólicos e do bem-estar de seus habitantes. Para que isso verdadeiramente aconteça esses autores propõem o chamado Plano Estratégico de Cidade, que, sem descartar a participação dos diversos atores urbanos (o que poderia ser uma posição de aparente interesse pela construção democrática da cidade), valoriza também as parcerias do público com o privado, medidas de rápida implementação, e construção de uma imagem da cidade; todos fatores que parecem se consubstanciar nos Grandes Projetos Urbanos ${ }^{4}$. Vale, para esse discurso, a idéia de "progresso" e da construção de ícones que integrem os diversos grupos da cidade ao redor de um projeto único, como num patriotismo urbano, um planejamento de pensamento único, pretensamente capaz de aglutinar ricos e pobres, o velho e o novo. Como afirmado por Carlos Vainer (in Arantes et al, 2000), a cidade torna-se então uma pátria e portanto deve gerar um grande consenso e um forte sentimento de se "pertencer", de "fazer parte", de não ser excluído.

Quase sempre estigmatizados como projetos de interesse de uma minoria capaz de apropriarse privadamente de seus resultados financeiros e como elementos de ações estratégicas de interesses políticos e econômicos ${ }^{5}$ os Grandes Projetos Urbanos acabam por ter seus aspectos positivos relegados a uma questão menor na discussão urbana atual.

A revisão desse enfoque, com a busca de redução dos riscos de perversidade de um megaprojeto, servindo-se da expertise até então desenvolvida para reduzir as externalidades do próprio planejamento urbano tradicional (coercitivo e regulador por meio sobretudo da legislação de uso e ocupação do solo), parecem ser necessárias na polêmica comumente observada. Evita-se aqui generalizações tentadoras como a de que os megaprojetos se apóiam em um discurso pós-moderno, apenas, ou seja, aquele 1) que vulgariza a história urbana por meio da simples revalorização cênica do patrimônio arquitetônico, 2) que valoriza pedaços da cidade, acreditando que com isso é capaz de valorizar o todo, e 3) que procura, por meio da criação de ícones de arquitetura e urbanísticos, agregar interesses opostos e "apaziguar" críticas e polêmicas contrárias a um determinado projeto político-paritidário.

\footnotetext{
${ }^{4} \mathrm{O}$ modelo proposto por esses autores, talvez na busca de discurso mais progressista, que os colocaria na defesa de críticas, defende também moradias populares, urbanização básica, serviços de saúde e educação, geração de emprego, dentre outras preocupações consideradas "sociais".

${ }^{5}$ É o caso do Planejamento Estratégico, ou então do Projeto Cidade, como fora chamado por Castells e Borja (1996)
} 
$\mathrm{Na}$ leitura dos casos aqui apresentados, essa leitura iniciou-se contestadora desse possível reducionismo crítico. Ao final, se faz conciliadora. De um lado, a evidência incontestável da perversidade de muitos desses projetos; de outro, seus potenciais inegavelmente transformadores.

\section{CONCEITUAÇÃO DE GRANDES PROJETO URBANOS}

Não se discute aqui as origens arquitetônicas e urbanísticas dos GPUs, como as do Movimento City Beautiful ou as mais pretéritas (como as transformações de Paris e Viena no século XIX), mas sim suas origens e contextualização no neoliberalismo dos anos 90 e o novo urbano dele decorrente. A partir de um modelo econômico e, sobretudo ideológico hegemônico, a cidade apresenta os instrumentais necessários para a consecução dessas idéias. Ainda que sem proceder a essa contextualização, Kenneth Powell (2000), em sua obra City Transformed, busca reconhecer as oportunidades possíveis para a implantação dos GPUs.assim, esse autor classifica as intervenções urbanas por meio de suas causas: 1.situações pós-guerra, 2. novas demandas por transporte, 3. crescimento da mancha urbana e 4. novas demandas culturais.

No Brasil, a inexistência de conflitos armados que destruam estruturas urbanas exclui a primeira possibilidade; a demanda não atendida por serviços de transporte que tem exigido a superutilização de estruturas existentes não permite a adoção de novos usos para edifícios e espaços tais como terminais de massa e exclui a segunda possibilidade ${ }^{6}$; o crescimento da mancha urbana nas cidades brasileiras com fortes características de periferização, fruto de uma ocupação aos pedaços, num mosaico de invasões e loteamentos exclui a terceira possibilidade de ser essa uma oportunidade de se alterar a cidade com Grandes Projetos. É na quarta possibilidade de causa que se observará a razão dos principais Grandes Projetos no cenário urbano nacional. De modo geral, os Grandes Projetos aqui observados acontecem em áreas tradicionais da cidade, subutilizadas, com forte referencial histórico, agora adaptadas para usos de lazer e cultura.

Se essas são algumas das situações que podem concretizar a implantação de GPUs, o estudo de suas características mais gerias permite apreende-los por meio de sete aspectos recorrentes. Nesta compilação, de caráter ainda a ser discutido e melhor comprovado, serviu-se da

\footnotetext{
${ }^{6}$ Alguns exemplos podem ser observados no caso de apropriação pelo poder municipal, depois de demoradas negociações, de espaços até então de propriedade da Rede Ferroviária Federal. Exemplos como o da renovação da Estação da Luz, em São Paulo, não significam a mudança de uso, ao contrário, valorizam o uso de terminal do edifício. O caso de Ponta Grossa / PR, com a utilização para lazer e valorização histórica de área central até então de propriedade da Rede Ferroviária, poderia ser considerada um exemplo desse novo uso.
} 
leitura de críticos de projetos nacionais e internacionais. Assim, essas sete características que satelizam o conceito e implantação mesmo dos atuais GPUs são:

1. Há um incremento na participação do setor privado, o qual agora conta com uma participação efetiva e mesmo decisiva para a implantação das obras. Arrisca-se mesmo dizer que o setor privado envolvido é sobretudo aquele envolvido com o capital imobiliário das áreas vizinhas e que vizualiza possibilidades de lucro de seus investimentos. Estado e setor privado estão juntos na inversão de recursos ${ }^{7}$.

2. Do ponto de vista histórico, são crescentes os custos envolvidos em GPUs. Mais importante ainda é reconhecer que se concretizam com custos em muito superiores àqueles originalmente pensados em suas fases propositivas ou a de elaboração dos projetos arquitetônicos e urbanísticos. Ou seja, tem sido comum, devido à complexidadade do projeto e da obra, assim como da imprevisibilidade de medidas mitigadoras resultado de negociações com agentes contrários ao projeto, o incremento nos valores inicialmente propostos. Taylor (in Althuler e Luberoff, 2003) demonstram acréscimos de 600\% entre 1960 e 1980 na execução de artérias urbanas expressas e de quatro vezes no custo de estádios de esporte entre 1950 e 1990. Do mesmo modo, afirmam os mesmos autores, a diferença entre o aprovado e aquele a ser despendido no projeto do Big Dig, em Boston, é de três vezes, para mais. Na construção do Aeroporto Internacional de Denver (outro GPU) os custos foram dobrados desde a sua aprovação nos anos 80 até sua implementação atual.

3. Processos de gentrification, os quais podem muitas vezes serem deliberadamente buscados nesses projetos. Desse modo, a revitalização da área implica intrinsecamente na mudança dos moradores originais: o projeto das classes média e alta toma o espaço das classes mais pobres ${ }^{8}$ não por meio de desapropriações, mas sim por mudanças de uso e, sobretudo pela valorização dos terrenos e edifícios urbanos. Sempre presente em diversas intervenções urbanísticas, como no caso das obras de Hausmann, em Paris, a gentrification assume novas feições a partir de revitalizações desencadeadas por grupos de artistas nos anos 70 nos Estados Unidos e, mais recentemente, nos projetos de Renascença Urbana do final dos anos 80 aos dias de hoje. Não é o objetivo deste artigo aprofundar o tema da gentrification e de sua relação com GPUs, todavia, tem-se como compromisso indicar a importância de sua inclusão no debate. De fato, na grande maioria das polêmicas sobre as GPUs, o tema é discutido com insistência. O caso emblemático das intervenções para revitalizar o patrimônio histórico de Bolonha, ainda nos anos 80 , com o intuito de transformá-la em centro cultural resultou na transformação de casas familiares em pontos comerciais de apoio a um turismo sofisticado; no caso das Docklands, antiga área desvalorizada com as mudanças no setor produtivo e

\footnotetext{
${ }^{7}$ Vide crítica feita por David Harvey em citação acima.

${ }^{8}$ Nos Estados Unidos, a gentrifictin ("the shame of the cities") pode significar também a transferência da posse de áreas entre diferentes etnias, mas sempre com a vinda de classes com poder aquisitivo mais elevado.
} 
desativação das atividades portuárias, com a posterior construção de grandes empreendimentos mobiliários, levou o custo da terra a um dos mais caros da Europa. Os exemplos seguem.

4. Uma característica importante e que pode garantir um potencial positivo aos GPUs é a possibilidade de integrar ou não um projeto maior para a cidade. Aí repousa, parece, a sua maior fonte de credibilidade. Uma vez integrado a um projeto maior de cidade, suas justificativas se ampliam e suas chances de provocar maiores impactos positivos são multiplicadas. Assim, algumas intervenções na área central de São Paulo, por exemplo, ganham valor ainda maior se analisadas no conjunto de intervenções e na justificativa de se otimizar a infra-estrutura atualmente disponível e subutilizada na capital paulista, tal qual outras grandes cidades brasileiras. Desse modo, a existência de um plano, formal ou não, de revalorização da área central, reposiciona os recursos investidos em reciclagem arquitetônica para o uso da arte, como a Pinacoteca do Estado, em facilidades para a cultura como a Estação Júlio Prestes, e mesmo a valorização da arquitetura pela arquitetura, como a revitallização da Estação da Luz. Se, em algum momento, tais processos poderiam ser questionados pela sua hierarquia na lista de prioridades de uma metrópole reconhecidamente deficitária em serviços urbano básicos, ao comporem uma idéia maior de cidade, seriam elementos importantes na melhoria de vida da cidade de forma geral.

5. Talvez o aspecto mais evidente relacionado com Grandes Projetos Urbanos é o fato de que são justificados, na maioria das vezes, pela necessidade de se recuperar áreas de subhabitação e pela necessidade de se valorizar símbolos importantes para a imagem e competitividade da cidade. Ao priorizarem áreas subtulizadas ou com padrão urbano abaixo do desejado, os GPUs tendem, na maioria das vezes a reforçar segregações - gentrification, mais uma vez. Tais fatos têm levado a comparações com polêmicas tais como aquelas ocorridas nas intervenções de Hausmann em Paris ou na Ringstrassen de Viena, contrapondo grupos localizados ideologicamente à esquerda e à direita. Lungo \& Smolka citam mesmo a possibilidade de haver uma reação por parte das elites urbanas em relação ao planejamento democrático, normativo, participativo e, sobretudo, afirmam, moroso. Mais uma vez, opõe-se o pragmatismo à discussão consorciada, o rápido ao demorado, o visível ao invisível. Numa visão menos maniqueísta, encontra-se a oposição entre aqueles que se desiludiram com os fracassos do planejamento normativo e que agora buscam nos grandes projetos urbanos sempre guardando as proporções e os recursos da cidade que o abriga e que o fabrica - o resultado necessário para atingir objetivos.

Os Planos Diretores fracassaram não só em São Paulo, mas em todo o Brasil e América Latina. Fracassaram não só porque eram falhos, mas porque tomaram os desejos pela realidade (Paul Singer, 1995, apud Flavio Villaça, 2005) 
A idéia do Plano Diretor existe no Brasil, pelo menos desde 1930... Desde então a idéia do Plano Diretor alastrou-se entre nós com grande intensidade ... é impressionante como um instrumento que nunca existiu na prática, possa ter adquirido tamanho prestígio por parte da elite do país. (Flávio Villaça, 2005 p 11)

6. Outro referencial que pode ser buscado para a construção de um conceito sobre Grandes Projetos Urbanos é aquele por apresentado por Alan Altshuler e David Luberoff (2003). Esses autores, na perspectiva da cidade americana, caracterizam os grandes projetos como os que apresentam grandes inversões de recursos públicos federais, em parceria com o capital privado, alavancados por grupos diversos de interessados e que são facilmente relacionados com a era do automóvel devido aos inúmeros exemplos na história recente americana, de tecidos urbanos alterados para dar lugar às novas demandas do transporte individual. No caso, o exemplo que talvez tenha inspirado os autores é a área central de Boston: nos anos 50, a construção do elevado Great Artery sobre sua área central "limpou" uma extensa área, relocando 20 mil pessoas e demolindo mais de mil edifícios. Nos anos 90 e 2000, as obras conhecidas como The Big Dig, ao enterrar o fluxo de veículos, liberam espaço para integração da malha urbana, permitem melhorias no tráfego, disponibilizam áreas para uso comercial, cultural, de escritórios e amenidades urbanas. Avaliadas em US\$14,6 bilhões, as obras são feitas sem desalojar famílias ou comerciantes na área. O exemplo desta obra serve também para diferenciar duas fases distintas na história mais recente das Grandes Intervenções Urbanas: nos anos 50, uma intervenção que prioriza o transporte individual e implica em grandes e irreversíveis impactos; nos anos 90, o transporte individual deve ao menos ser isolado e sua prioridade dá lugar à busca da integração de compartimentos urbanos e ao respeito à população original.

7. Os resultados positivos que se espera de um grande projeto, devem, pois constantetemente fazer frente aos impactos urbanos ambientais e sociais. Se antes, era aceitável, até certo ponto, aceitar declarações como a do prefeito de Nova York, Robert Moses de que "you can not make an omelete without breaking the eggs" é agora substituído pelo "no harm project", considerando que estudos prévios e medidas mitigadoras são capazes de reduzir os impactos negativos da obra e mesmo de seu uso. Nos Estados Unidos e em muitos outros países, incluindo Brasil, tais posturas resultam de uma forte crítica a impactos gerados por grandes obras. Internacionalmente e no Brasil, a resposta técnica e legal é a exigência de elaboração de documentos de análise prévios, tais como os

\footnotetext{
${ }^{9}$ Citação de Robert A Caro, na obra The power broker: Robert Moses and the fall of New York. New York: Alfred A Knopf, 1974
} 
Relatórios de Impacto Ambiental. Assim, o grande número de obras que ora se observa em nível internacional na chamada Renascença Urbana é antecedido por uma quase estagnação que resultou do ambiente eufórico dos anos 50 e de seus impactos negativos.

\section{GRANDES PROJETOS URBANOS NO BRASIL}

Tomando-se os anos 90 como um recorte histórico onde, com maior ou menor sucesso, com maior ou menor apropriação de seus resultados pela população, vê-se repetir nas cidades brasileiras o empreendimento de grandes projetos de valorização e revitalização de áreas centrais degradadas, de setores históricos subutilizados, de áreas com potencial turístico, dentre outros. Nem sempre intervenções de grande monta (recursos, área e volume de obra), podem ser considerados Grandes Projetos Urbanos pelo impacto gerado nas cidades (muitas de pequeno e médio porte) e pela sua constituição em ponto referencial urbano ${ }^{10}$. O mapeamento desses projetos é um esforço que vai além do propósito e das condições do presente artigo. Todavia, consciente dessa dificuldade e desprovido da prepotência de se cobrir todos as intervenções urbanas que poderiam ser classificadas como GPUs no Brasil, a seleção, construída sobretudo pela disponibilidade da informação, procurase aqui identificar alguns aspectos generalizantes contribuintes ao debate urbano.

Outros estudos críticos sobre projetos, no entanto, foram buscados para enriquecer essa discussão: a revitalização por meio de inúmeras obras no centro de São Paulo, Programa de Recuperação do Centro Histórico de Salvador, Plano de Revitalização do Recife antigo, o projeto do Parque da Maternidade, em Rio Branco, Acre, e algumas intervenções de menor publicidade em cidades de pequeno e médio porte. Outros projetos, evidentemente, poderiam ser incluídos, como a iniciativa da construção de um plano estratégico no Rio de Janeiro, onde o Museu Guggenhein é um elemento importante, as diversas ações observadas ao longo dos últimos 30 anos em Curitiba, largamente reconhecida pela sua valorização do urbanismo imagético, da valorização da orla em Fortaleza, Ceará e tantos outros que não contaram com a mesma visibilidade no debate acadêmico ou inserção na mídia.

A análise das informações sobre os 3 GPUs aqui descritos buscam confirmar ou desacreditar algumas das características que parecem acompanhar a discussão sobre esses projetos. A seleção deu-se devido à disponibilidade de estudos e é fortemente limitada pela falta de pesquisas realizadas com intuitos comparativos serve, tão-somente, para iniciar uma discussão preliminar sobre o tema e

\footnotetext{
10 Seria esse talvez o aspecto melhor definidor dos G\}Pus: mais caracterizados pelo impacto relativo gerado que pela grandeza da obra analisada de forma descontextualizada.
} 
limita-se àquilo descrito nos textos selecionados. As experiências são: Projeto Lagoinha em Belo Horizonte, Obras na orla de Belém do Pará, e as reformas na área portuária de Baltimore. Os textos são: As dinâmicas da reabilitação urbana: impactos do projeto Lagoinha, de Fernanda Borges de Moraes e Maurício Guimarães Goulard, Cidade e Cultura na Amazônia Brasileira, de Saint-Clair Cordeiro da Trindade Júnior, e o livro Spaces of Hope, de David Harvey. A escolha desse terceiro se justifica pelo fato de discutir um exemplo simbólico na discussão sobre GPUs e referência história internacional provocadora de inúmeros debates. As conclusões aqui apresentadas são uma leitura dos textos selecionados. O objetivo dessa análise não é o de estudar o projeto de maneira específica, mas sim de confrontá-lo com outros semelhantes e buscar construir referenciais comuns aos GPUs urbanos da atualidade brasileira.

\section{PROJETO: REABILITAÇÃO INTEGRADA DO BAIRRO LAGOINHA, BH}

\section{Referência textual:}

As dinâmicas da reabilitação urbana: impactos do projeto Lagoinha, de Fernanda Borges de Moraes e Maurício Guimarães Goulard ${ }^{11}$, publicado in Cadernos de Arquitetura e Urbanismo da PUC Minas (2002).

\section{Obra:}

Ações diversas no asssentamento suburbano da então recém-planejada e construída cidade de Belo Horizonte. O bairro Lagoinha após ter sido sucessivamente alterado por diversas obras de interesse metropolitano em detrimento de interesses locais (canalização de córregos, abertura de avenidas, instalação da rodoviária da capital e construção de túnel) é motivo de obras de revalorização no final dos anos 90 , quando das comemorações do centenário da cidade. No discurso, o bairro seria valorizado como patrimônio urbano, cultural e arquitetônico, incluindo: recuperação de imóveis isolados, quarteirões, vias públicas e áreas públicas; programas de revitalização econômica estimulando a permanência de atividades empresariais no mesmo local; programa de revitalização cultural, participação comunitária. As obras e ações são, pois pensadas em projeto de reabilitação integrada, capaz de simbolizar e de resgatar a história de Belo Horizonte.

\footnotetext{
${ }^{11}$ Fernanda Borges de Moraes é arquiteta, professora do Depto de Arquitetura e Urbanismo da UFMG, mestre em Geografia pela UFMG e doutora pela FAUSP. Maurício Guimarães Goulard é arquiteto pela UFMG e técnico da Secretaria Municipal de mio Ambiente de Uberlândia / MG. Os contatos dos autores são: fbmoraes@arq.ufmg.br / fbmoraes@ufmg.bre gggemeos@bol.com.br.
} 


\section{Polêmicas relatadas no texto:}

Inicialmente, os autores contextualizam o caso Lagoinha em um cenário onde várias cidades brasileiras, nos anos 90, mobilizam-se para recuperar áreas centrais; em sua maioria, detentoras de importante valor cultural e histórico. Fundamentadas num discurso de "melhoria da qualidade de vida da população", não contam com estudos que possam avaliar seus resultados uma vez implantadas essas ações. Ficam para ser discutidas a sua apropriação pelo cidadão e a sua implantação e manutenção pelo estado.

Tal qual observado em outras análises, as ações no bairro Lagoinha, a despeito de suas especificidades, podem ser também inseridas num entendimento de que compõem uma "espetacularização" do urbano, tal qual a criação da própria cidade de Belo Horizonte, a qual "representou à época a realização de um projeto pioneiro ... um centro irradiador de progresso e expressão de um novo modelo de vida urbana" (autores citados).

Dos propósitos das ações junto ao bairro da Lagoinha, teve-se quatro grandes programas: Requalificação Ambiental, com recuperação de imóveis privados e áreas públicas; Requalificação Econômica para estimular a permanência dos moradores originais e diversificar atividades; Revitalização Cultural, fortalecendo e resgatando práticas locais; e Envolvimento Urbano e Social, com incentivo à participação da comunidade na discussão daquilo que é de seu interesse. Na análise da efetivação desses propósitos do projeto original, o estudo relata a má conservação de imóveis que teriam tido suas fachadas recuperadas, limitação espacial dessa iniciativa de recuperação, com reflexos no padrão e na conservação do patrimônio arquitetônico, a não implantação de todas as obras previstas, como o caso da Praça do Centenário, a falta de confiança comunitária na ação popular, o fracasso dos programas de desenvolvimento econômico, a descontinuidade das ações governamentais, a fraca inserção do mercado imobiliário, a vinculação do projeto a cronogramas de interesse político-eleitoral, o risco de museificação do espaço do bairro, as desarticulações das ações, o privilégio pelo projeto, do registro histórico do bairro em detrimento de aspectos que possam garantir ou incentivar a convivência comunitária.

Desta lista de problemas, chama a atenção a recorrência da crítica quanto à dificuldade de se atender a "demandas contemporâneas por novas funções urbanas, inerente à dinâmica das cidades, e a necessidade de preservação desses espaços enquanto registro histórico e locus de práticas sociais, pressupostos nem sempre tratados de forma equilibrada". (autores citados). Uma equação que pende para, mais uma vez, a espetacularização e museificação dos espaços urbanos.

Do ponto de vista da administração das ações aí propostas, chama a atenção também a constatação de que houve descoordenação "entre programas e projetos desenvolvidos por diferentes 
órgãos ou instâncias [as quais] podem produzir efeitos ainda mais catastróficos" (autores citados). Assim, a necessária ação integrada, um caminho para a ação mais global na cidade, sujeita-se obrigatoriamente a estruturas administrativas de ação setorial, exclusiva e com capacitações e interesses diferenciados. Nesse sentido, os pesquisadores lembram que um projeto como o Lagoinha, "cujas diretrizes, além de entrarem frontalmente em choque com os planos de reestruturação viária e de transportes, com a prevalência das diretrizes pautadas por esses últimos, não alcançaram as metas previstas". (autores citados).

Em comunicação posterior com este autor, Fernanda Borges de Moraes ainda reitera dois aspectos que julga dos mais importantes: a falta de uma discussão maior do projeto e de seu fracasso e a contribuição negativa para a descrença nas ações de governo.

"O mais grave ainda, em relação à Lagoinha, é o fato de se tratar de uma área pericentral. Se fosse no centro de $\mathrm{BH}$, o fracasso do projeto teria uma maior visibilidade e poderia ter provocado alguma reação mais contundente. Afinal, é preciso explicitar os erros e problemas para saná-los. Como o bairro era apenas lindeiro a uma avenida de grande fluxo (seu interior restringia-se a um trânsito local) e nele permanecia o estigma da prostituição, da pobreza e, ainda, havia uma violenta favela muito próxima, o restante da cidade ficou alheio à questão. Não se comoveu! Acabaram as comemorações do centenário e tudo ficou como estava, senão pior."

"a descrença dos moradores e usuários do bairro em relação às ações de planejamento e gestão. Não se trata apenas da interrupção sofrida no projeto e no fracasso dos programas, mas o problema maior foi abrir um processo e não levá-lo adiante".

\section{PROJETO: OBRAS NA ORLA DE BELÉM DO PARÁ}

\section{Referência textual:}

Cidade e Cultura na Amazônia Brasileira, de Saint-Clair Cordeiro da Trindade Júnior ${ }^{12}$, disponibilizado pelo autor

Obra:

Série de obras realizadas para valorização da orla da cidade de Belém, de iniciativa, não integrada, dos governos estadual e municipal. O conjunto dessas obras é composto por: Projeto Ver-

\footnotetext{
12 O autor é professor pesquisador junto ao Departamento de Geografia, Universidade Federal do Pará, mestre em Planejamento do Desenvolvimento, pela UFPA e doutor em Geografia, pela USP, conta com diversos outros trabalhos relacionados ao tema, esclarecedores e obrigatórios para o aprofundamento do tema. Contato: stclair@amazon.com.br
} 
o-Rio, Estação das Docas, Complexo do Ver-o-Peso, Terminal Fluvial Turístico da Praça Princesa Isabel, e Projeto Cidade Criança. Notar que quase sempre implementados de forma pontual, aquilo que se pode considerar Grande Projeto Urbano, em Belém, constitui um conjunto de obras que persegue um constante ideário de valorização da água para a cidade. Em comunicação com este autor, Saint-Clair Cordeiro da Trindade Júnior coloca em dúvida o fato de se considerar esses projetos como Grandes Projetos Urbanos, afirmando que "na verdade, para a realidade da cidade, eles causam um impacto relevante, mas não se tratam de grandes intervenções urbanas, senão de intervenções pontuais e, na sua maioria, com apelos turísticos e para projetar uma imagem da cidade ao sabor do mercado e do consumo".

\section{Polêmicas encontradas no texto:}

A contextualização feita para esses projetos é a de uma cidade - fato repetido em inúmeros outros exemplos no país - que, em sua história mais recente, refuta sua relação com o rio, a despeito de sua densa malha hídrica, e que agora, servindo-se da cultura e da natureza como "pontos fortes do marketing urbano" procura uma valorização desses espaços e cria um cenário que não corresponde com exatidão ao passado idealizado. De modo geral, a orla é hoje um espaço valorizado pelo seu aspecto imagético e pelo aspecto locacional devido a constituir-se em acesso a atividades econômicas, pela beleza de suas formas naturais e de seu potencial para amenidades urbanas.

As obras de Belém aqui analisadas, a despeito de parecer constituir um conjunto ao observador desavisado, é apresentado no texto como ação pontual, fruto de um planejamento feito em partes, por meio de simples "janelas para o rio" e não por meio de uma cidade integrada na sua totalidade e com veracidade a esse recurso natural. A correção da primeira constatação é feita com a informação de que a aparência de uma política global para a cidade resulta mais de coincidências estratégicas dos governos que as realizaram que propriamente de um projeto único, e assim formatado, de cidade.

O antigo contato diário da população com a malha dentrítica da cidade, importante para os acessos inter e intramunicipais, o verdadeiro cenário do passado urbano, hoje, é apenas resgatado por um cenário de espetacularização, tal qual igualmente criticado em outros projetos de outras cidades. São "intervenções urbanísticas que programam a vida urbana formatando-a a partir de formas espaciais e desenhos urbanos que não necessariamente potencializam a espontaneidade da vida cotidiana" (autor citado). Se o discurso oficial que acompanha esses projetos, seja os da prefeitura, seja os do governo do estado, é o de resgate da relação cidade-rio, na prática, eles se concretizam apenas como uma vitrine com a imagem que se quer mostrar da cidade. 
Tais posturas, na realidade, correspondem ao interesse de uso turístico que, mais uma vez, também é observado em outros projetos de outras cidades brasileiras: para tanto, servem-se de "marcas arrojadas ... quando se leva em conta a concepção arquitetônica e urbanística. Desses exemplos, o mais paradigmático é o complexo turístico-cultural Estação das Docas, pensado a partir do aproveitamento e refuncionalização dos galpões desativados do antigo porto". (autor citado).

Nesse sentido, a cultura, diferentemente do passado, passa a ser o elemento que estabelecerá a relação cidade-rio, por meio de um urbanismo que reforça "valores culturais e representações sociais que formatam compartimentos e definem a utilização de espaços públicos com verdadeiras subtrações do direito à cidade" (autor citado).

O rio que era usado em atividades cotidianas, agora se transforma num elemento de contemplação, a dimensão ribeirinha agora limita-se a residuais de uma vida urbana que não mais existe e é representada por alguns simples elementos arquitetônicos e paisagísticos que tentam reconstituir a vida amazônica.

Por último, o autor apresenta ainda um aspecto nem sempre discutido a respeito de Grandes Projetos Urbanos, estando, pois, esse aspecto relacionado com a forma de gestão da cidade em diversas outras de suas atividades: é a geração de empregos a partir da implementação desses projetos. Se nos projetos Ver-o-Rio, Praça do Pescador (integrante do Complexo Ver-o-Peso), há uma tentativa de se adotar uma economia solidária, incentivando cooperativas de trabalhadores e pequenos empreendedores, no Projeto das Docas, a prioridade é dada a grupos de empreendedores que já demonstram um bom desempenho econômico, mais aptos a responder aos interesses de um consumidor seleto.

Resumidamente, observa-se na leitura do texto: valorização da cultura de fragmentos da vida amazônica, a crença no turismo como renovador da economia, a importância dada à criação de um cenário urbano que favoreça o marketing da cidade, e, o que é mais importante aqui, a possibilidade de se ganhar, mais, menos, ou de favorecer grupos seletos ou grandes setores da cidade (por meio de uma economia seletiva ou solidária), a depender dos interesses ideológicos de governo. 


\section{PROJETO: REVITALIZAÇÃO DA ÁREA CENTRAL DE BALTIMORE}

\section{Referência textual:}

Spaces of Hope, de David Harvey ${ }^{13}$, livro publicado em 2000, pela University of California Press. Berkeley.

Obra:

Um dos exemplos mais citados em termos de Grandes Projetos Urbanos, inserindo-se mesmo nas origens da chamada Renovação Urbana, ou, em inglês, Urban Renewal, dos anos 90, a cidade de Baltimore é objeto de inúmeros estudos, alimentando um dos temas mais freqüentes na crítica urbana norte-americana atual: gentrification. David Harvey, nesta obra, a qual critica a visão derrotista de que "não há alternativas", analisa com recorrência as transformações urbanas implementadas em Baltimore.

As obras iniciam-se com a iniciativa de um grupo de investidores a partir do final dos anos 50 e posteriormente adotada pela Prefeitura. O plano proposto visava a renovação de quarteirões centrais. Com essa atração, conservam-se edifícios históricos não tombados e surgem novos investimentos em área até então degradada e subutilizada. O interior dos quarteirões é liberado para usos públicos e comerciais e garagens públicas no sub-solo. Surgem também passarelas para pedestres interligando os prédios. Em 1961, Mies Van der Rohe ganha a concorrência para propostas imobiliárias e seu prestígio chama a atenção para o que acontecia na cidade. Tal processo é completado nos anos 80 , com da construção de prédio no último terreno livre. A continuidade administrativa e a reeleição por quatro vezes do prefeito Schaeffer foram fundamentais nesse processo. Hoje, análises alertam para os elevados índices de criminalidade, fuga de moradores e atividades comerciais.(adaptado de Vicente Del Rio, 2001)

\section{Polêmicas encontradas no texto:}

Servindo-se inúmeras vezes do caso de revitalização da área central de Baltimore, de onde o autor é egresso, David Harvey fundamenta sua hipótese de que a política e a ideologia contemporâneas são dominadas por injustiça e segregações sociais, parecendo mesmo não haver alternativas. A despeito dessa descrença, a qual é alimentada pelo desalento observado na Baltimore

\footnotetext{
${ }^{13}$ David Harvey é ex- professor-pesquisador na área de geografia na Johns Hopkins University e fellow na London School of Economics. Largamente utilizado na crítica urbanística brasileira, é autor de inúmeros trabalhos, dentre os quais The Condition of Postmodernity (1989), publicado em português pelas Edições Loyola.
} 
pós-reciclada e recém decadente, Harvey, ao final do livro apresenta uma utopia possível, proposta para o milênio que se anuncia.

A revitalização de Baltimore, segundo pesquisas deste autor, parece ter seu sucesso reduzido, sendo agora palco para a gentrificacion, crimes, expulsão de moradores originais, apropriação privada dos lucros, e, novamente, museificação e espetacularização. Nesse sentido, o autor revisita seus próprios trabalhos anteriores: "A cidade colagem é agora o tema, e a revitalização urbana substitui a vilificada renovação urbana como a palavra-chave do léxico dos planejadores" (David Harvey, 1996, p 46)

Estatísticas usadas pelo autor e referente a situações pré e pós intervenções, inserem a cidade de Baltimore como "the city where ideals have frayed and there appears to be no alternative" ((David Harvey, 2000, p 157). Na realidade, tal constatação parece se repetir em muitos outros estudos.

Baltimore has some of the nation's finest schools, but they're all private and so are denied to most children. The city has growing homelessness, yet also 40,000 boarded-up houses. It has one of the world's best medical centers and public health schools, yet "life-expectancy is abysmally low and the health statistics in the immediate environs of these institutions tell an appalling story of impoverishment, marginalization, exploitation, and neglect." Baltimore has a glitzy waterfront and a swanky new sports stadium that guzzled gallons of public money, but soup-kitchen lines lengthen and inner-city missions are stretched beyond coping.(Andy Merrifield, 2006)

Numa crítica pouco velada aos arquitetos responsáveis pelas obras, o autor propõe um exercício que concilie o "prazer" individual do arquiteto em efetivar sua utopia por meio da revisão da ocupação do espaço com os interesses cotidianos de quem habita a cidade.

Imagine ourselves as architects, all armed with a wide range of capacities and powers, embedded in a physical and social world full of manifest constraints and limitations, imagine also that we are striving to change that world, as crafty architects bent on insurgency we have to think strategically and tactically about what to change and where, about how to change what and with what tool, but we also have somehow to continue to live in this world, this is 
fundamental dilemma that face everyone interested in progressive change" (David Harvey, 2000, p 233).

Na realidade, a crítica de Harvey vai além daquela que parece se dirigir aos riscos de um Grande Projeto Urbano, inserindo-os mesmo numa forma de cidade e de planejamento que são sintetizadas em expressões significativas: the urban spectacle as a commodity, yuppie utopia, gentrification and renewal e sua implicações perversas, ou seja, as chamadas bourgeios utopias, as quais se espacializam em interminável e dispendioso spraw"..

\section{ALGUMAS CONCLUSÕES}

Pretensioso ensaiar aqui qualquer síntese de como são entendidos os Grandes Projetos Urbanos, ainda que limitado ao caso brasileiro. Permite-se ousar, no entanto, que, nessa curta análise, alguns temores se repetem com evidência. Esses são os mesmos que parecem acompanhar os projetos de renovação urbana desde suas origens mais recentes: a perversa valorização do interesse privado sobre o coletivo e a valorização da imagem, ainda que falsa. $\mathrm{Na}$ valorização do interesse privado, o instrumental mais útil e eficiente são os discursos que valorizam os valores das parcerias público-privadas. Para a valorização da imagem, a arquitetura surge como forte aliado instrumental na construção de ícones e construção de imagens.

Além disso, há ainda a crítica dirigida a propósitos não realizados: planos que falham em seus próprios objetivos, independentemente se discutíveis ou válidos. É o fracasso das administrações públicas em levar adiante um projeto que se diz transformador da cidade. A compatibilidade entre o estratégico proposto e a capacidade de o poder público agir nesse sentido parece elemento de difícil constatação nos Grandes Projetos Urbanos no Brasil.

Todavia, se refutáveis em princípio, pouco vale a discussão sobre os Grandes Projetos Urbanos. Se corrigíveis, parece haver concordância de que devem ser pensados com transparência, evitando a clássica crítica da malversação de recursos públicos. Se corrigíveis, devem igualmente ser propostos segundo a visão maior da cidade, numa estratégia avançada e integradora de vários setores.

Sobra arriscar algo sobre prioridades no espaço urbano, porém essa é arriscada demais. Se colocados frente a frente de necessidades básicas, tal qual um exercício de simples matemática 
social, serão sempre refutáveis, tornando desnecessária até mesmo a discussão desses Projetos. Este autor propõe a continuidade da discussão. 


\section{REFERÊNCIAS}

Althuler e Luberoff, The changing politics of urban Meg-projects. Land Lines: Lincoln Institute of Land policy. Boston: october, 2003 Vol 15, N 4

Arantes, Otília. Urbanismo em fim de linha: e outros estudos sobre o colapso da modernização arquitetônica. São Paulo: Edusp, 1998. 224 p

Arantes, Otília; Vainer, Carlos, Maricato, Erminia. A cidade do pensamento único. Desmanchando consensos. Petrópolis RJ- Brasil: Ed. Vozes, Coleção Zero à Esquerda, 2000

Castells, Manuel \& e Borja, Jordi. "As cidades como atores políticos", em Revista Novos Estudos CEBRAP, N 45, julho/ 1996, SP, p 152/166

Borges de Moraes, Fernanda \& Goulard, Maurício Guimarães. "As dinâmicas da reabilitação urbana: impactos do projeto Lagoinha", em Cadernos de Arquitetura e Urbanismo, V 9, N 10, Dezembro, 2002. p 51-71. PUC Minas, Belo Horizonte

Caro, Robert A, The power broker: Robert Moses and the fall of New York. New York: Alfred A Knopf, 1974

Del Rio, Vicente. Voltando às origens. A revitalização de áreas portuárias nos centros urbanos. Disponível em <www.vitruvius.com.br/arquitextos> Acesso em jan. 2006

Harvey, David. Spaces of Hope. University of California Press. Berkeley, 2000

A Condição Pós-moderna. Edições Loyola, São Paulo, 1996

Lungo, Mario e Smolka, Martin O. Land value and large urban projects: the Latin American experience. Land Lines: Lincoln Institute of Land policy. Boston: January, 2005 Vol 17, N 1:

Long, Judith Grant. 2002. Full count: the real cost of public funding for major league sports facilities and why some cities pay more to play. PhD dissertersation, Harvard University.

Lungo, Mario. \& Smolka Martin Macroproyectos urbanos: desafíos para las ciudades latinoamericanas. Land line newsletter: Lincoln Institute. Vol. 14, ㄲo4, 2002.

Land Value and Large Urban Projects: The Latin American Experience. Land line newsletter: Lincoln Institute, Vol 17, no 1, 2005.

Merrifield, Andy. No Exit? Dream on. < http://www.yorku.ca> Acesso em Fev., 2006.

Taylor, Brian, 1995. Public perceptions, fiscal realities and freeway planning: the California case. Journal fo the American Plannnig Association 61 (1): 43-56 
Ultramari, Clovis. O novo Museu de Oscar Niemeyer: a obra do arquiteto pelo olho do operário. Cadernos de Arquitetura e Urbanismo. PUC Minas, Belo Horizonte, V 11, N. 12. Dez 2004.

Trindade Júnior, Saint-Clair Cordeiro da, Práticas e representações espaciais na orla fluvial de Belém / PA. Memo

Villaça, Flávio. (1999). Uma contribuição para a história do planejamento urbano no Brasil em Deák, C. \& Schiffer, S. R.(orgs). O processo de urbanização no Brasil. São Paulo: EDUSP-FUPAM : 169-243.

As llusões do Plano Diretor. Disponível em
<http://www.usp.br/fau/fau/galeria/paginas/index.html>. Acesso em jan de 2006. 